with other pituitary hormones, as determined by bioassay methods, has not yet been investigated.

This method for preparing growth hormone uses only very mild conditions and involves a minimum number of steps. It has been applied successfully to the preparation of grow th hormone from quantities of fresh, whole glands, ranging from $7 \mathrm{gm}$. to $200 \mathrm{gm}$. and using columns containing 20 gm. $-150 \mathrm{gm}$. of DEAE-cellulose. There appears to be no difficulty in extending the method to either smaller or larger quantities of starting material.

A. L. C. WALlace

Ian Clunies Ross Animal Research Laboratory,

Division of Animal Physiology,

Commonwealth Scientific and Industrial

Research Organization,

Prospect,

New South Wales.

Wilhelmi, A. E., Hypophysial Growth Hormone-Nature and Actions, edit, by Smith, Gaebler and Long (McGraw-Hill, 1954).

2 Papkoff, H., and Li, C. H., Biochim. Biophys. Acta, 29, 145 (1958).

${ }^{3}$ Li, C. H., Evans, H. M., and Simpson, M. E., J. Biol. Chem., 159 $353(1945)$.

Wilhelmi, A. E., Fishman, J. B., and Russell, J. A., J. Biol. Chem., $176,735(1948)$.

\section{Acute Effect of Three Antibiotics on Diuresis in the Rat}

ONE of the side effects limiting the use of some polymyxins is renal toxicity.

Sodium colistinmethanesulphonate, a new antibiotic with a spectrum of activity very similar to that of the polymyxins, but with much lower systemic toxicity ${ }^{1}$, was investigated for its effects upon urinary volume output and was compared in this respect with two polymyxins.

The influence of the administration of each antibiotic upon diuresis was estimated by measuring, after treatment, the urinary output in $\mathrm{ml} . / \mathrm{kgm} . / \mathrm{hr} ., 2$ and $5 \mathrm{hr}$. after administration of a water load. This was done in groups of 20 male Wistar rats of approximately $360 \mathrm{gm}$. which were used twice consecutively in the following manner : first, the normal urinary volume output figures were determined for each group ; 2 days later, the same procedure was repeated, each group receiving subcutaneously its respective antibiotic treatment at the same time as the intragastric water load. Each time the rats were starved (food and water) for $18 \mathrm{hr}$. before intragastric administration of a $50 \mathrm{ml} . / \mathrm{kgm}$. tap water load. The animals were then placed in metabolic cages without food and water and their urinary excretion was recorded at 2 and $5 \mathrm{hr}$., aggregated, and computed as indicated in Table 1.

The results at 2 and $5 \mathrm{hr}$. indicate that a very marked inhibition of diuresis occurred with all doses of either polymyxin $B$ or colistin sulphate up to $1.67 \mathrm{mgm}$./kgm., whereas doses of sodium colistinmethanesulphonate up to $1.67 \mathrm{mgm}$. $/ \mathrm{kgm}$. tended. to increase diuresis. However, inhibition of diuresis was observed also with sodium colistinmethanesulphonate at doses above $1.67 \mathrm{mgm}$. $/ \mathrm{kgm}$., but it was necessary to administer as much as $16.7 \mathrm{mgm} . / \mathrm{kgm}$. in order to obtain a degree of inhibition similar to that noted with $1.67 \mathrm{mgm}$. of the two other antibiotics. This indicates that, of the three antibiotics tested, sodium colistinmethanesulphonate interferes much less with urinary function, a fact that may explain its higher margin of safety.

R. J. GIRERD

C. L. RASSAERT

Department of Physiology,

Warner-Lambert Research Institute, Morris Plains, New Jers эy.

${ }^{1}$ Schwartz, B. S., Warren, M. R., Barkley, F. A., and Landis, L., Antibiotics Annual, 1959-1960, 41 (Antibiotica, Inc., New York, 1960).

\section{Preparation and Properties of Purified House Dust Allergen}

Although house dust allergens have been the subject of many investigation, ${ }^{1}$, attempts to establish the chemical identity of the specific house dust antigen thus far have met with very little success. This is partly due to the complex nature of crude house dust extracts, which, apart from non-specific toxic substances, contain many other allergens as well (derived from feathers, human and animal dandruff, etc.).

Boatner and Efron ${ }^{2}$ were among the first to indicate the general protein nature of active preparations from house dust. Rimington et al..$^{3}$, in a more detailed study, obtained a purified dust fraction which was found to contain two electrophoretically distinct components of similar chemical composition and skin reactivity. The substance was found to give both protein and carbohydrate reactions. Recently, Vannier and Campbell ${ }^{4}$ reported the isolation of a purified dust allergen which they estimated to contain 95 per cent carbohydrate and 5 per cent protein.

Table 1

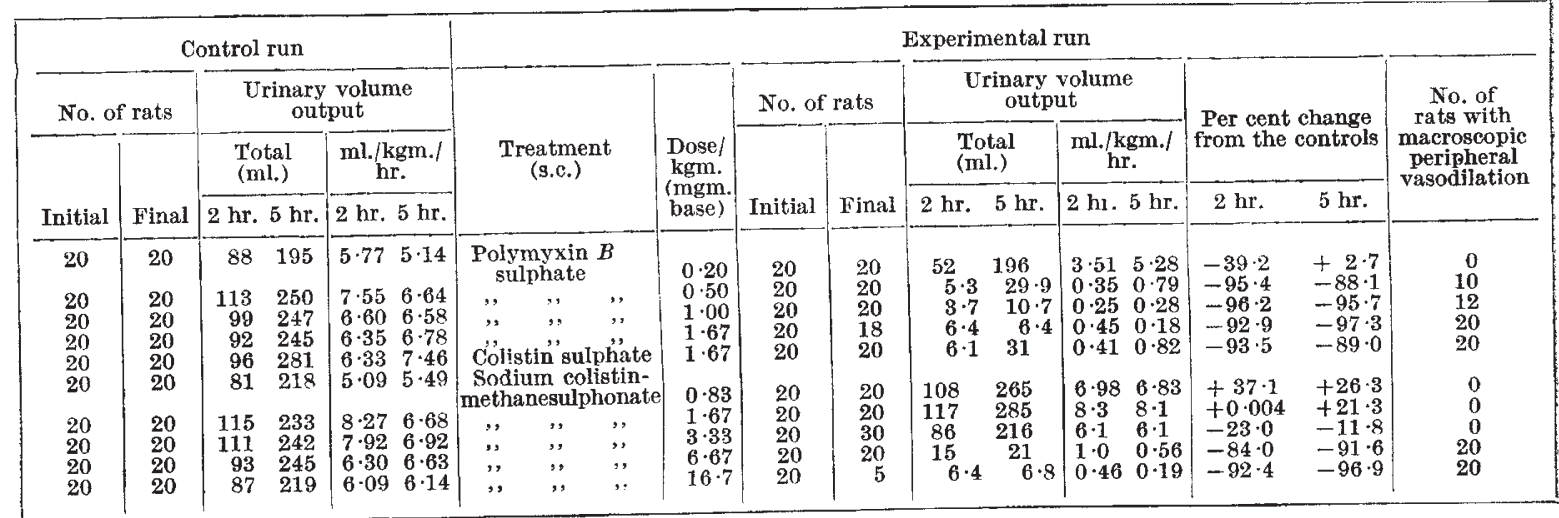

